\title{
Myopathy due to Myoadenylate Deaminase Deficiency
}

National Cancer Institute

\section{Source}

National Cancer Institute. Myopathy due to Myoadenylate Deaminase Deficiency. NCI

Thesaurus. Code C157504.

An autosomal recessive condition caused by mutation(s) in the AMPD1 gene, encoding AMP deaminase 1. The condition is characterized by exercise-induced muscle pain and/or fatigue, which may be associated with rhabdomyolysis and/or increased concentrations of creatinine kinase. 